\title{
Metformin promotes apoptosis in hepatocellular carcinoma through the CEBPD-induced autophagy pathway
}

\author{
Hsin-Hwa Tsai ${ }^{1, *}$, Hong-Yue Lai ${ }^{2, *}$, Yueh-Chiu Chen ${ }^{3, *}$, Chien-Feng $\mathrm{Li}^{4}$, Huei-Sheng \\ Huang ${ }^{5}$, Hsiao-Sheng Liu6 ${ }^{6}$ Yau-Sheng Tsai ${ }^{7}$, Ju-Ming Wang ${ }^{1,8}$ \\ ${ }^{1}$ Institute of Bioinformatics and Biosignal Transduction, National Cheng Kung University, Tainan, Taiwan \\ ${ }^{2}$ Institute of Basic Medical Sciences, National Cheng Kung University, Tainan, Taiwan \\ ${ }^{3}$ Department of Pharmacology, National Cheng Kung University, Tainan, Taiwan \\ ${ }^{4}$ Department of Pathology, Chi-Mei Medical Center, Tainan, Taiwan \\ ${ }^{5}$ Department of Medical Laboratory Science and Biotechnology, National Cheng Kung University, Tainan, Taiwan \\ ${ }^{6}$ Department of Microbiology and Immunology, National Cheng Kung University, Tainan, Taiwan \\ ${ }^{7}$ Institute of Clinical Medicine, National Cheng Kung University, Tainan, Taiwan \\ ${ }^{8}$ Graduate Institute of Medical Sciences, Taipei Medical University, Taipei, Taiwan \\ *The authors contributed equally to this work
}

Correspondence to: Ju-Ming Wang, email: yumingw@mail.ncku.edu.tw

Keywords: HCC, autophagy, apoptosis, CEBPD, metformin

Received: May 30, $2016 \quad$ Accepted: January 04, $2017 \quad$ Published: January 13, 2017

\section{ABSTRACT}

Metformin, as an AMP-activated protein kinase (AMPK) activator, can activate autophagy. A study showed that metformin decreased the risk of hepatocellular carcinoma (HCC) in diabetic patients. However, the detailed mechanism in the metformin-mediated anticancer effect remains an open question. Transcription factor CCAAT/enhancer-binding protein delta (CEBPD) has been suggested to serve as a tumor suppressor and is responsive to multiple anticancer drugs in HCC. In this study, we found that CEBPD and autophagy are involved in metformin-induced cell apoptosis in Huh7 cells. The underlying mechanisms in this process included a reduction in Src-mediated CEBPD protein degradation and an increase in CEBPDregulated $\angle C 3 B$ and $A T G 3$ gene transcription under metformin treatment. We also found that AMPK is involved in metformin-induced CEBPD expression. Combined treatment with metformin and rapamycin can enhance autophagic cell death through the AMPK-dependent and AMPK-independent pathway, respectively. Taken together, we provide a new insight and therapeutic approach by targeting autophagy in the treatment of HCC.

\section{INTRODUCTION}

Autophagy is a conserved intracellular degradation process in which cellular organelles are degraded by lysosomes and recycled to replenish cells with energy in stress environments. As an essential regulator of cellular homeostasis and adaptation of stresses, autophagy plays an important role in carcinogenesis including hepatocellular carcinoma (HCC). Although the role of autophagy in hepatocarcinogenesis remains controversial [1,2], studies have demonstrated the crucial role of autophagy in liver disease. Therefore, understanding the details of the involvement of autophagy in HCC is crucial to help facilitate the development of future therapeutic approaches to HCC.
Autophagy related genes (ATGs) are vital for phagophore formation, and microtubule-associated protein light chain 3 (LC3B, also known as ATG8) is one of the most important phagophore components. Several specific substrates are preferentially degraded by autophagy. Of these, the best-known protein is $\mathrm{p} 62$ [also known as sequestosome 1 (SQSTM1)]. In HCC, p62 expression increases, and the autophagy response is impaired [3]. In addition, enhanced LC3B can be a strong prognosis factor [4]. However, the regulation of ATGs and their involvement in HCC cancer cells remain largely uncharacterized.

Metformin, a biguanide class of oral hypoglycemic agents, is the first line drug for the treatment of type 2 diabetes mellitus [5]. Epidemiological studies reported that 
metformin can reduce the risk of HCC occurrence [6-8]. Metformin also induces G1 phase arrest and apoptosis in $\mathrm{HCC}[9,10]$. Metformin is an AMP-activated protein kinase (AMPK) activator and can activate autophagy via a reduction in the mammalian target of rapamycin (mTOR) signaling pathway [11]. Previous studies demonstrated that metformin-induced autophagy performs a proapoptotic role in melanoma and lymphoma $[11,12]$. However, the detailed mechanisms linking autophagy and apoptosis in the metformin-mediated anticancer effect on $\mathrm{HCC}$ remain an open question.

CCAAT/enhancer-binding protein delta (CEBPD) is a transcription factor that belongs to the CCAAT/ enhancer-binding protein family. Several studies demonstrated that CEBPD expression is downregulated in breast cancer [13], leukemia [14], cervical cancer [15], and hepatocellular carcinoma [16]. CEBPD is thought to be a potent tumor suppressor, as its overexpression can result in the death of cancer cells. For instance, CEBPD can upregulate proapoptotic genes, including PPARG2 and GADD153, in cervical cancer [15] and caspase-8 and caspase- 3 in prostate cancer [17]. Thus, activating CEBPD expression in cancer cells could be a strategy for cancer therapy.

\section{RESULTS}

\section{Autophagy involves in metformin-induced cell apoptosis in Huh7 cells}

To dissect the details of metformin function in liver cancer cells, we first assessed the survival effect on Huh7 cells. The results showed that the growth arrest and apoptosis of Huh7 cells were coordinately increased following the metformin treatment (Figure 1A and Supplementary Figure 1A). Meanwhile, lower doses of metformin induced growth arrest, indicating that apoptosis should follow the induction of growth arrest in response to higher doses of metformin (Figure 1B and Supplementary Figure 1B). We next assessed whether the activation of autophagy was also responsive to metformin. To address this issue, characteristic hallmarks of autophagy were examined in Huh7 cells. We found that the LC3B-II/ LC3B-I ratio was increased and p62 expression was reduced in metformin-treated Huh7 cells (Figure 1C). In addition, metformin increased the numbers of LC3B puncta in Huh7 cells that were transfected with GFP-LC3B expression vectors (Figure 1D). Activation of autophagy can lead to either cell survival or death [18]. Currently, the role of autophagy in metformin-mediated apoptosis of liver cancer cells is unknown. To address this, LC3B was knocked down by lentiviruses with shLC3B. An MTT assay showed that LC3B knockdown restored metformininhibited cell viability in Huh7 cells (Figure 1E).
Furthermore, LC3B knockdown attenuated metformininduced cell apoptosis, as demonstrated by flow cytometry propidium iodide (PI) staining and TUNEL assay, and repressed metformin-induced caspase-3/7 activation in Huh7 cells (Figure 1F, 1G and Supplementary Figure 1C). This result was confirmed by treatment with an autophagy inhibitor (chloroquine, CQ), which inhibits both the fusion of autophagosomes with lysosomes and lysosomal protein degradation [19]. Treatment with CQ also restored metformin-inhibited cell viability and repressed metformin-induced caspase-3/7 activation in Huh7 cells (Supplementary Figure 2A and 2B). Taken together, these results suggest that autophagy plays a pro-apoptotic role in the metformin-mediated anticancer effect in Huh7 cells.

\section{CEBPD participates in metformin-mediated anticancer effects in Huh7 cells}

Previous results showed that CEBPD expression was upregulated by several clinical anticancer drugs in Huh7 and HepG2 cells [15]. Here, we found that CEBPD expression was also induced by metformin in liver cancer cells (Supplementary Figure 3). To verify whether CEBPD contributes to the metformin-induced anticancer effects, a loss-of-function assay in which CEBPD was knocked down by shRNA was performed. Loss of CEBPD attenuated metformin-induced cytotoxic activity in Huh7 cells (Figure 2A), indicating that CEBPD contributed to metformin-inhibited cell viability. Moreover, the processes of apoptosis (Figure 2B and Supplementary Figure 1D) and G1 arrest (Figure 2C) contributed to CEBPD-mediated antiproliferation activity upon metformin treatment. The upregulation and downregulation of the CEBPD responsive genes cyclin D1 [20] and p27 [21], respectively, were observed following CEBPD attenuation upon metformin treatment (Figure 2D).

\section{Metformin induces CEBPD protein stabilization via reduced Src activity}

Several studies indicated that CEBPD abundance can be regulated in a transcription-dependent $[16,22]$ or -independent manner [23]. We found that metformin had no effect on the regulation of CEBPD transcription (Supplementary Figure 4A and 4B) but affected its protein stability (Figure 3A). We next tested whether Src kinase-increased proteasome degradation [23] contributed to metformin-induced attenuation of CEBPD protein degradation. Metformin inhibited Src activity and enhanced CEBPD expression (Figure 3B). Moreover, the inhibition of Src kinase by a Src inhibitor (SKI-606) enhanced CEBPD abundance (Figure 3C). These results suggest that loss of Src activity contributes to stabilization of CEBPD protein upon metformin treatment. 


\section{CEBPD participates in metformin-induced autophagy}

As shown above, activation of both autophagy and CEBPD was observed in metformin-treated liver cancer cells. However, the association between the transcription factor CEBPD and autophagy activation remained unknown. Increase in CEBPD can enhance the LC3B-II/ LC3B-I ratio and reduce p62 expression in Huh7 cells
(Figure 4A). Moreover, loss of CEBPD reversed metforminenhanced LC3B-II/LC3B-I ratio and metformin-reduced p62 expression (Figure 4B). In addition, increased numbers of LC3B puncta were observed in Huh7 cells exogenously expressing CEBPD (Figure 4C, upper panel), but the signal indicating LC3B puncta formation was reduced in CEBPD-knockdown Huh7 cells upon metformin treatment (Figure 4C, lower panel). These findings suggested that CEBPD is involved in metformin-induced autophagy.
A

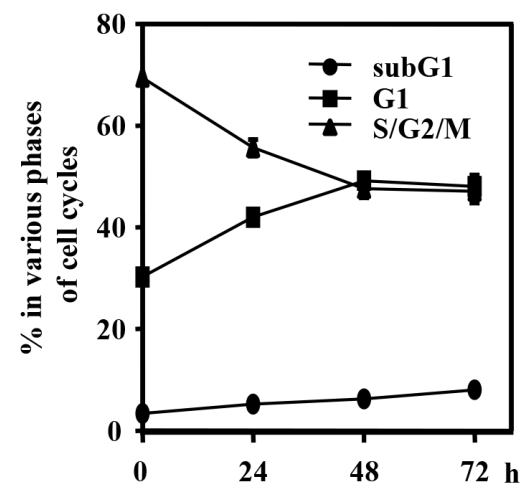

B



C

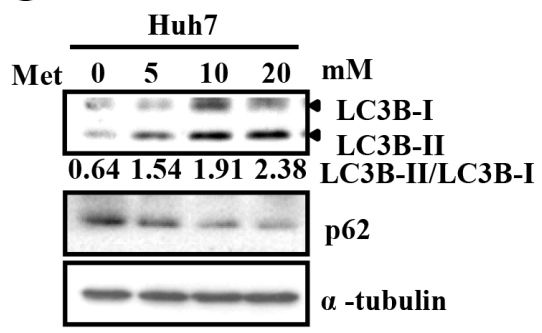

D
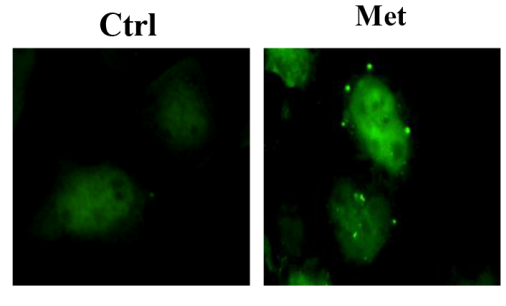



$\mathbf{E}$

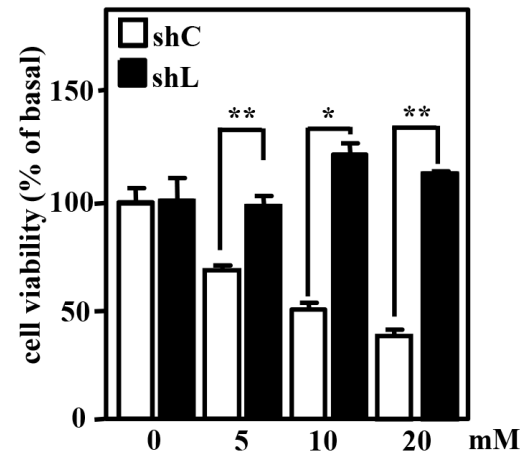

F

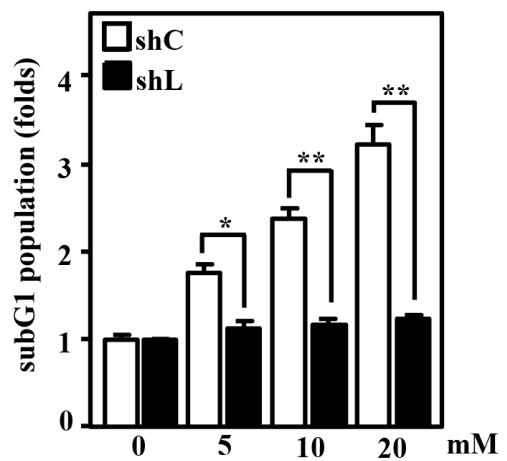

G

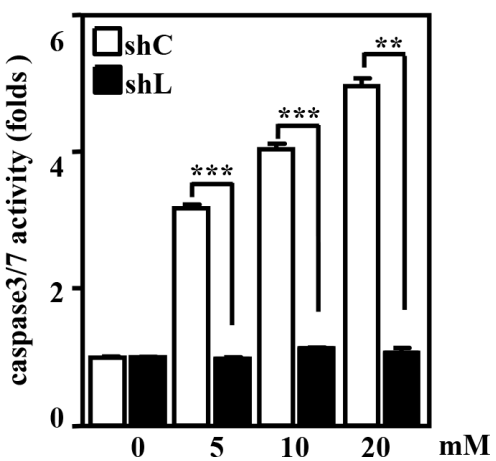

Figure 1: Autophagy plays a pro-apoptotic role in metformin-treated Huh7 cells. (A) Huh7 cells were treated with metformin (Met, $5 \mathrm{mM}$ ) for 24, 48 and $72 \mathrm{~h}$ or $(\mathbf{B})$ treated with Met $(5,10$ and $20 \mathrm{mM}$ ) for $48 \mathrm{~h}$. Experimental cells were collected at the indicated concentrations and time points, stained with propidium iodide, and analyzed by flow cytometry. (C) Huh7 cells were treated with Met $(5 \mathrm{mM})$ for $6 \mathrm{~h}$ and harvested for Western blot analyses. (D) Huh7 cells were transfected with GFP-LC3B expression vectors and then treated with or without Met $(5 \mathrm{mM})$ for $6 \mathrm{~h}$. The numbers of LC3B puncta were evaluated under a fluorescence microscope. (E) Huh7 cells were infected with lentiviruses encoding shLacZ (shC) or shLC3B (shL) for 3 days. The cell viability of infected experimental cells was measured by MTT assays after $48 \mathrm{~h}$ of Met treatment at the indicated concentrations. (F) The apoptotic activity of these experimental cells was analyzed by flow cytometry PI staining. (G) The caspase-3/7 activity of these experimental cells was detected by CellEvent caspase-3/7 green detection reagent. 


\section{CEBPD activates $L C 3 B$ and $A T G 3$ gene transcription in Huh7 cells}

In addition to increase in the LC3B-II/LC3B-I ratio and reduction of p62 expression, the expression of ATG3 (the catalytic enzyme in LC3BI/II conversion) and total LC3B were also increased in CEBPD-overexpression Huh7 cells (Figure 4A). This observation led us to test whether CEBPD activated $L C 3 B$ and $A T G 3$ gene transcription. $L C 3 B$ and $A T G 3$ reporter activities were induced in metformin-treated Huh7 cells (Figure 5A). Meanwhile, CEBPD knockdown attenuated metformininduced $L C 3 B$ and $A T G 3$ reporter activities (Figure 5A). The result of a serial deletion reporter assay showed that potent CEBPD responsive regions were located at $-978 /-618$ and $-1179 /-537$ on the $L C 3 B$ and $A T G 3$ gene promoters, respectively (Figure 5B). Furthermore, the in vivo DNA binding assay demonstrated that CEBPD bound to the promoter regions of $L C 3 B$ and $A T G 3$ genes (Figure 5C). Next, a fused LC3B promoter-driven GFPLC3B expression vector was constructed to assess whether CEBPD can induce LC3B puncta formation through activating $L C 3 B$ transcription. The numbers of $\mathrm{LC} 3 \mathrm{~B}$ puncta increased and decreased following exogenous CEBPD increase and attenuation, respectively, with or without metformin treatment. Moreover, after deleting the CEBPD responsive region on the $\mathrm{LC} 3 \mathrm{~B}$ promoter, the numbers of LC3B puncta did not change following the exogenous increase of CEBPD (Figure 5D). Taken together, these results suggest that CEBPD activates the $L C 3 B$ and $A T G 3$ gene transcription and increases LC3B puncta formation in a transcription-dependent manner.

\section{Combined treatment of metformin and rapamycin enhances the anticancer effects}

A previous finding revealed that the activation of autophagy may enable residual cancer cells to resist chemotherapy and allow tumor relapse and progression [24]. However, excessive autophagy has been implicated in cell death [25]. Combined treatment to enhance the activity of autophagy is one choice for cancer therapy. Rapamycin, an mTOR inhibitor [26], has been suggested to serve an autophagy activator [27]. Western blot analyses showed
A
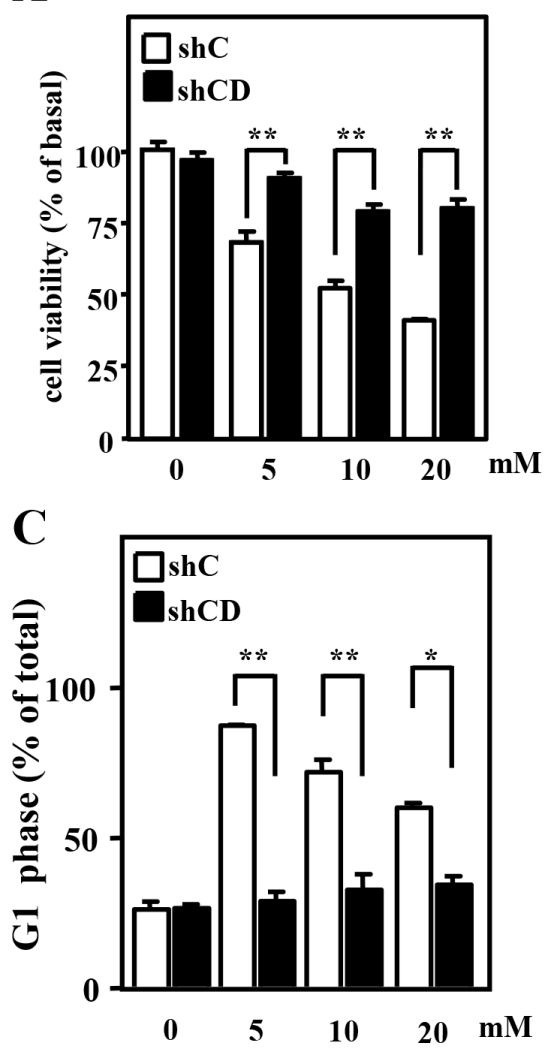

B



D



Figure 2: CEBPD contributes to metformin-induced cell cycle arrest and cell apoptosis in Huh7 cells. (A) Huh7 cells were infected with lentiviruses encoding shLacZ (shC) or shCEBPD (shCD) for 3 days. After treating with metformin (Met) at the indicated concentrations $(5,10$ and $20 \mathrm{mM}$ ) for $48 \mathrm{~h}$, the cell viability of infected experimental cells was measured by MTT assays. (B) The apoptotic activity of the experimental cells was analyzed by flow cytometry PI staining. (C) The G1 phase of these experimental cells was analyzed by flow cytometry. (D) Huh7 cells were infected with lentiviruses encoding shLacZ (shC) or shCEBPD (shCD) for 3 days. After treating with or without Met $(5 \mathrm{mM})$ for $6 \mathrm{~h}$, the lysates were harvested for Western blot analyses. 
that treatment with an AMPK inhibitor (compound C) suppressed metformin-induced AMPK phosphorylation and CEBPD expression, whereas rapamycin had no effect on AMPK phosphorylation and CEBPD expression in Huh7 cells (Supplementary Figure 5A). These results implied that metformin and rapamycin work via different pathways in autophagy activation. To check whether combined metformin and rapamycin treatment could enhance anticancer effects, cell viability and apoptosis were measured by MTT assay and flow cytometry PI staining, respectively. The MTT assay showed that combined metformin and rapamycin treatment reduced Huh7 cell viability further than individual treatment (Supplementary Figure 5B). Moreover, this combination significantly increased Huh7 cell apoptosis compared to metformin or rapamycin treatment alone (Supplementary Figure 5C). The results suggest that combined metformin and rapamycin treatment can enhance liver cancer cell death in vitro.

\section{Combination of metformin and rapamycin elicits stronger cytotoxicity in xenograft model}

We further evaluated the effect of combined treatment compared to individual treatment in human tumor xenograft mouse model. Rapamycin elicited side
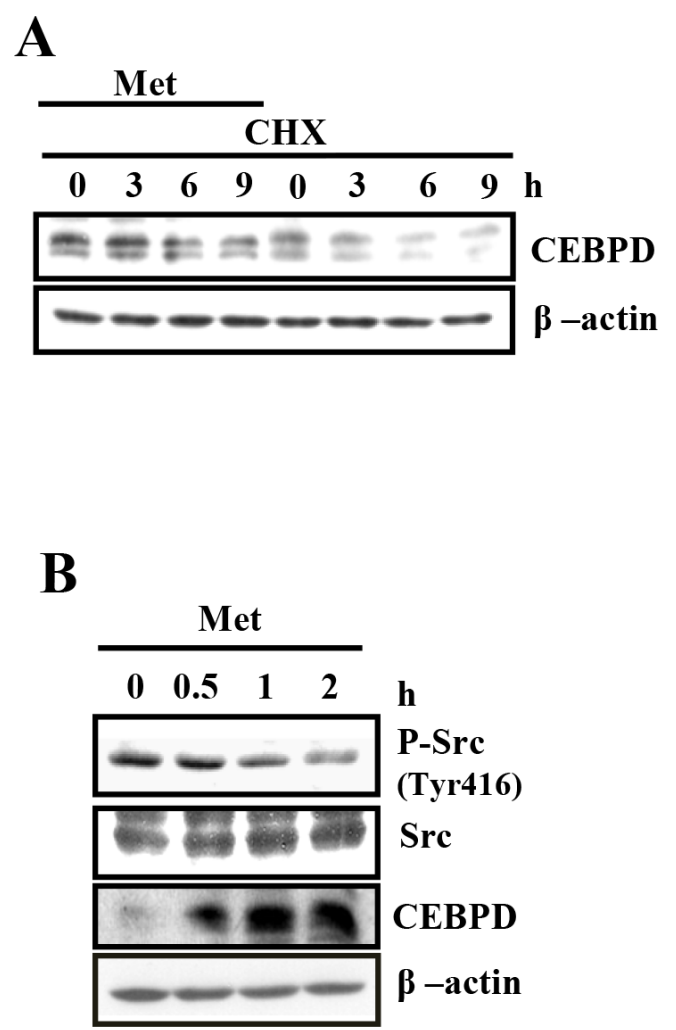

effects when used clinically [28]. We used relatively lower clinical doses of rapamycin combined with metformin to treat Huh7 cell xenografts in NOD/SCID mice. In the Huh7 cell xenograft model, treatment with metformin or rapamycin inhibited tumor growth compared with control. Moreover, combined metformin and rapamycin treatment produced significantly enhanced antitumor activity compared with single-agent treatment (Figure 6A). Importantly, mice tolerated the combined treatment well, as no body weight loss was observed during or after treatment (Supplementary Figure 6). Furthermore, the CEBPD protein level was examined in lysates extracted from these experimental xenograft tumors. The result showed that CEBPD abundance was induced with metformin treatment alone and combined treatment (Figure 6B). Moreover, comparing with their individual controls (Figure 6C, compare lane 1 with lane 2 and lane 3 with lane 4), loss of CEBPD significantly enhanced the growth of xenografted Huh7 tumor in NOD-SCID mice, suggesting that CEBPD indeed plays an antitumor role. Importantly, loss of CEBPD also attenuated the dual treatment-enhanced killing effect, further suggesting its response to metformin-induced killing effect (Figure 6C, compare lane 1 with lane 3 and lane 3 with lane 4).
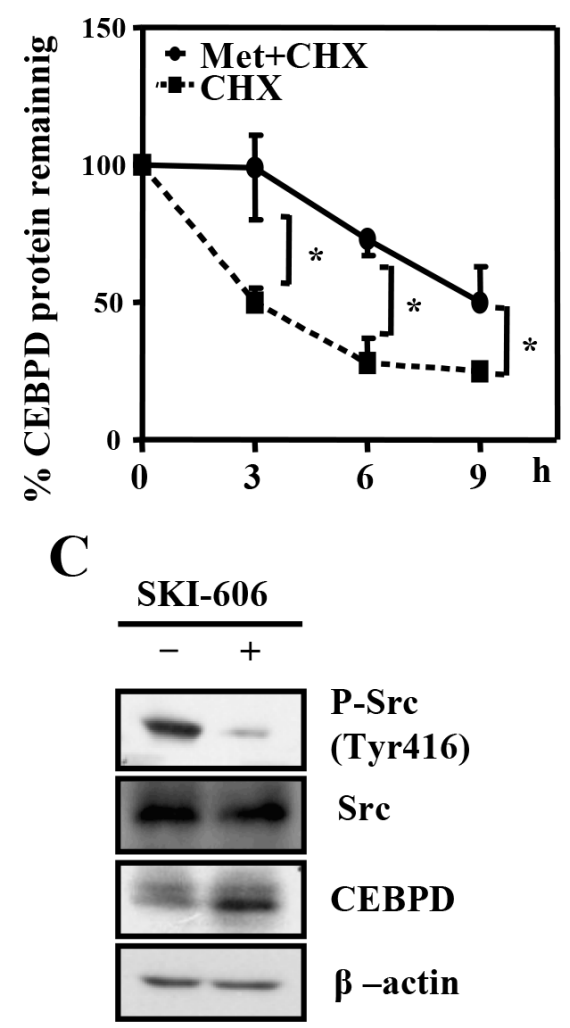

Figure 3: Metformin stabilizes CEBPD protein through reduced Src activity in Huh7 cells. (A) Huh7 cells were pretreated with or without Met $(5 \mathrm{mM})$ for $2 \mathrm{~h}$ and then treated with cyclohexamide $(\mathrm{CHX}, 10 \mu \mathrm{g} / \mathrm{ml})$ to inhibit de novo synthetic proteins. Protein lysates were extracted at the indicated time points, and the remaining proteins were analyzed by Western blotting. (B) Huh7 cells were treated with Met $(5 \mathrm{mM})$ at indicated time points or $(\mathbf{C})$ treated with SKI-606 for $24 \mathrm{~h}$. The experimental cell lysates were harvested for Western blot analyses. 


\section{DISCUSSION}

Autophagy is a conserved process by which cytoplasmic components are degraded by lysosomes. It is commonly seen as a cytoplasmic event, and nuclear events were not considered of primary importance for this process until now. In light of the recent findings on transcription factors EB (TFEB) [29], E2F1 [30], forkhead box O1 (FOXO1) [31], activating transcription factor 4 (ATF4) [32], CCAAT/enhancer-binding protein- $\beta$ (C/EBP $\beta)$ [33] and C/EBP-homologous protein (CHOP) [34], we propose that a complex transcriptional network is involved in autophagy. The main function of most of the aforementioned factors is the transactivation of autophagyrelated genes, including $L C 3 B$, allowing a sustained level of autophagy flux in the cells. However, the transcriptional activation of $A T G 3$, which is indispensable for LC3BI/II conversion, is less characterized. Importantly, we identified
CEBPD as a novel activator of $\angle C 3 B$ and $A T G 3$ gene transcription. This is also the first study to demonstrate that transcriptional activation of autophagy-related genes contributes to the induction of apoptosis.

$\mathrm{Src}$ is a non-receptor tyrosine kinase that is upregulated in many types of cancer. The roles of Src in promoting tumor progression and metastasis have been well documented [35]. The most prominent and wellstudied function of Src is its extensive interaction with transmembrane receptor tyrosine kinases (RTKs). Src interacts with epidermal growth factor receptor (EGFR), human epidermal growth factor receptor 2 (HER2 or ErbB2), platelet-derived growth factor receptor (PDGFR), insulin-like growth factor-1 receptor (IGF-1R) and c-Met/ hepatocyte growth factor receptor (HGFR) [36]. Several studies have indicated that inhibition of EGFR tyrosine kinase or Src kinase can induce autophagy in cancer cells $[37,38]$. Moreover, metformin inhibits the expression

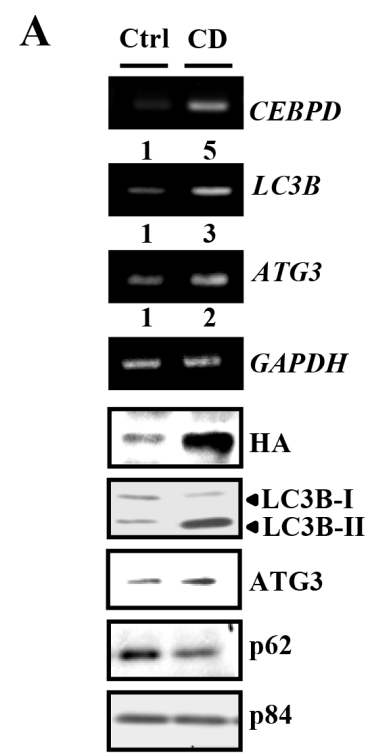

C

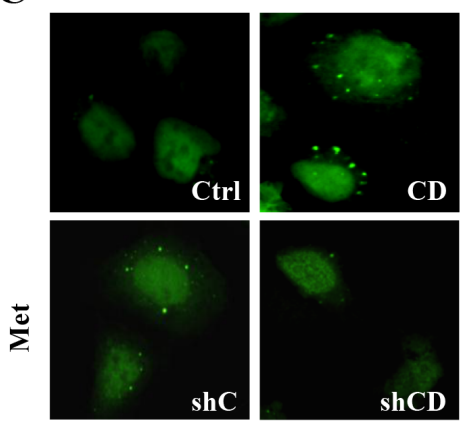

B
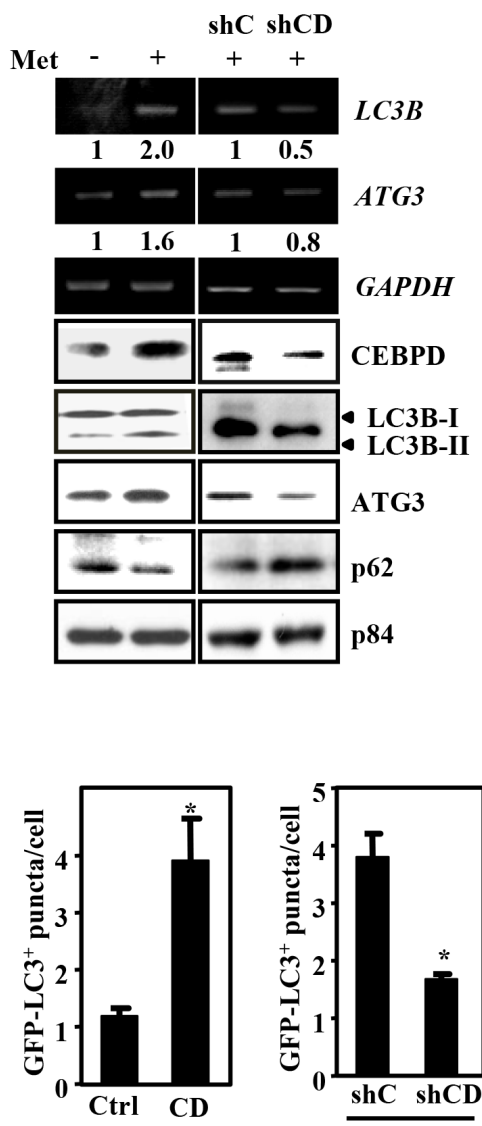

Figure 4: CEBPD is involved in metformin-induced autophagy. (A) Huh7 cells were transfected with pcDNA3/HA (Ctrl) or pcDNA3/HA-CEBPD (CD) expression vectors or (B) infected with lentiviruses encoding shLacZ (shC) or shCEBPD (shCD) and then treated with or without metformin (Met, $5 \mathrm{mM}$ ). The lysates and total RNA were harvested for Western blot analyses and RT-PCR, respectively. (C) GFP-LC3B expression vectors were co-transfected with pcDNA3/HA (Ctrl) or pcDNA3/HA-CEBPD (CD) expression vectors into Huh7 cells (upper panel). Huh7 cells that were pre-infected with lentiviruses encoding shLacZ (shC) or shCEBPD (shCD) were transfected with GFP-LC3B expression vectors and then treated with Met $(5 \mathrm{mM})$ for $6 \mathrm{~h}$ (lower panel). The numbers of LC3B puncta were evaluated under a fluorescence microscope. 
A

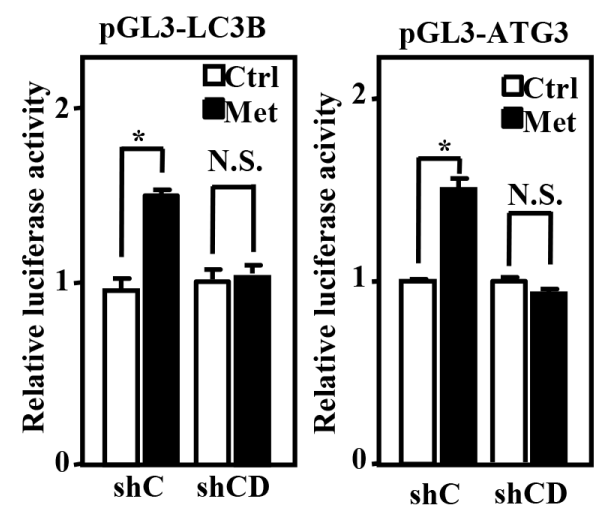

C



D

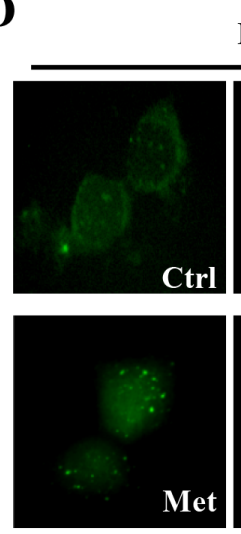

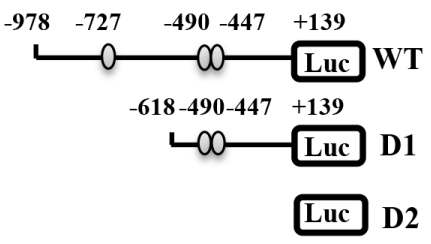
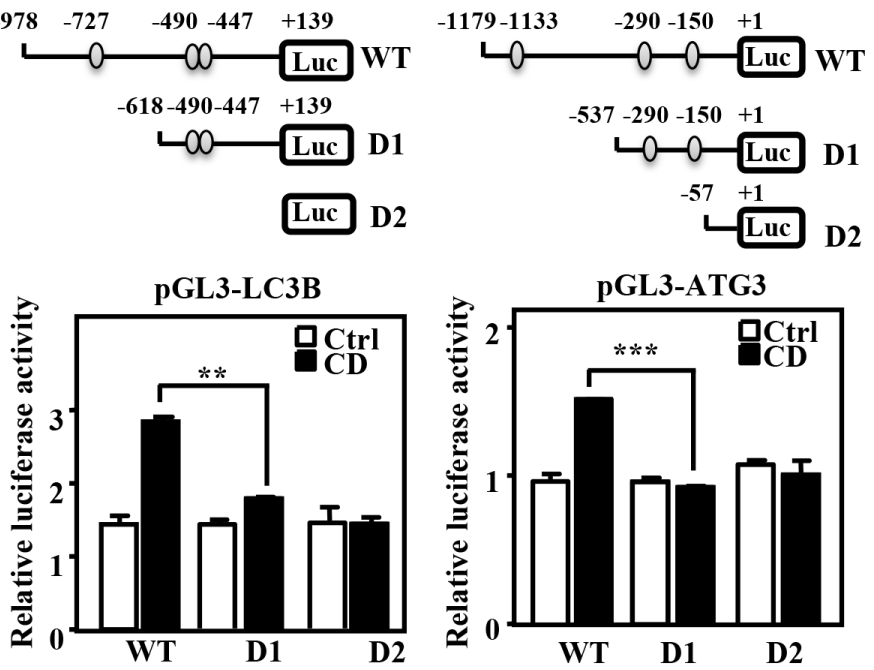

LC3B reporter
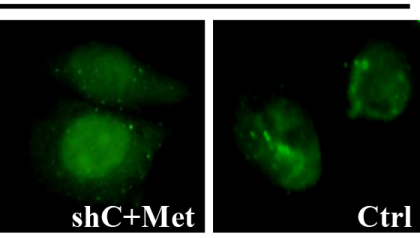

mut LC3B

reporter
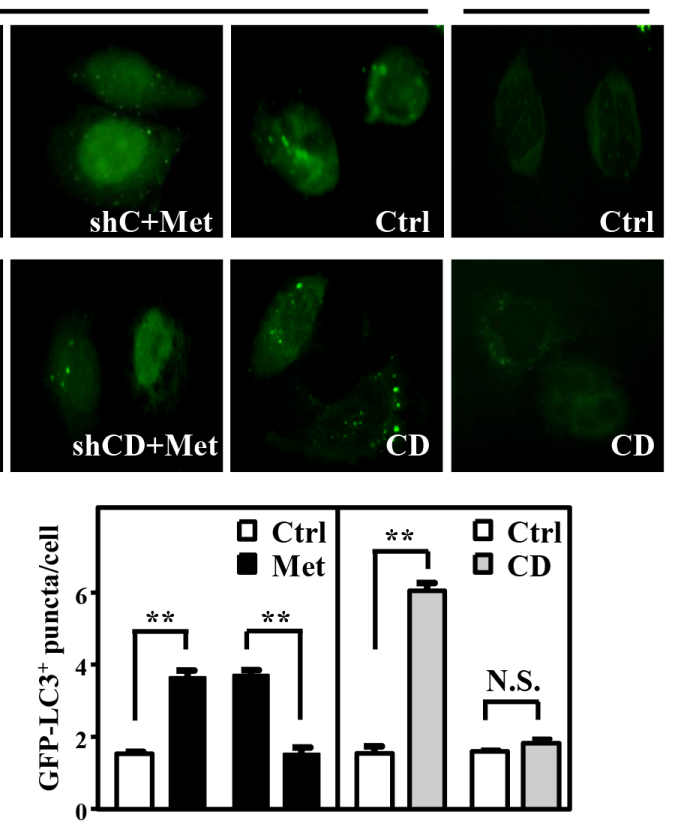

$\mathrm{LC} 3 \mathrm{~B}$ reporter ++++++-

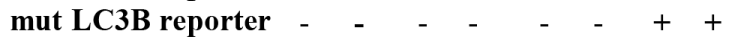

$\operatorname{shC}-\quad-\quad+\quad-\quad-\quad-$

Figure 5: CEBPD activates $L C 3 B$ and $A T G 3$ gene transcription and induces exogenous LC3B puncta formation. (A) Huh7 cells that were pre-infected with lentiviruses encoding shLacZ (shC) or shCEBPD (shCD) were transfected with $L C 3 B$ or ATG3 reporters and then treated with or without metformin (Met, $5 \mathrm{mM}$ ). The lysates of experimental transfectants were harvested for luciferase assays. (B) Various $5^{\prime}$ serial deletion $L C 3 B$ or $A T G 3$ reporters were co-transfected with pcDNA3/HA (Ctrl) or pcDNA3/HA-CEBPD (CD) expression vectors into Huh7 cells. The lysates of experimental transfectants were harvested for luciferase assays. (C) Huh7 cells were treated with or without Met $(5 \mathrm{mM})$ for $6 \mathrm{~h}$. As a positive control, PCR amplification was also performed using 1/20 of the input DNA from chromatin before the immunoprecipitation (IP) step. Chromatin was isolated from cells, and the IP step was performed using a CEBPD antibody. (D) Huh7 cells or Huh7 cells that were pre-infected with lentiviruses encoding shLacZ (shC) or shCEBPD (shCD) were transfected with LC3B promoter-driven GFP-LC3B expression vectors (LC3B reporter) and then treated with or without Met (5 mM) (Left panel). LC3B promoter-driven GFP-LC3B expression vectors (LC3B reporter) or CEBPD binding site-deleted LC3B promoterdriven GFP-LC3B expression vectors (mut LC3B reporter) were co-transfected with pcDNA3/HA (Ctrl) or pcDNA3/HA-CEBPD (CD) expression vectors into Huh7 cells (Right panel). The numbers of LC3B puncta were evaluated under a fluorescence microscope. 
of the EGFR family in tamoxifen-resistant breast cancer cells [39]. These reports provide potential explanations why metformin could inhibit Src activity, as observed in this study (Figure 3B).

Epigenetic effects attenuated CEBPD expression in HCC $[15,16]$. As mentioned above, loss of Src activity contributes to stabilization of CEBPD protein. This discovery indicates that the attenuation of CEBPD could also result from increased CEBPD protein degradation. However, this hypothesis requires further investigation. In addition, CEBPD has been suggested to serve as a potent tumor suppressor [40]. Strong CEBPD activation could strengthen the death of liver cancer cells [15]. CEBPD activation can be downregulated by Src kinase activity, as shown in this study. Therefore, the potential of Src inhibitor-containing combinatorial regimens can be tested in HCC following the rationale of activating and stabilizing CEBPD in cancer cells.
Many cancers develop resistance to chemotherapy drugs under single treatment, which is a major factor in the failure of many forms of chemotherapy [41]. Combinatorial use of metformin and dichloroacetate (DCA) promotes B leukemic cell death [42], and suppresses the growth of ovarian cancer cells [43]. Moreover, metformin enhanced apoptosis induced by paclitaxel and cisplatin in endometrial cancer [44]. Metformin, as an AMPK activator, can also activate autophagy in cancer cells [12, 45-47]. AMPK is an essential mediator of the tumor suppressor LKB1 and could be suppressed in cancer cells [48]. In this study, we found that AMPK is involved in metformin-induced CEBPD expression. However, rapamycin had no effect on AMPK activation in myotubes [49], which is consistent with our findings. Therefore, combined metformin and rapamycin treatment can enhance autophagic cell death through AMPK-dependent and AMPK-independent


Figure 6: Combination of metformin and rapamycin elicits stronger cytotoxicity in xenograft model. Huh7 cells were subcutaneously inoculated into NOD-SCID mice, followed by an intraperitoneal injection of vehicle, metformin (Met, $250 \mathrm{mg} / \mathrm{kg} / \mathrm{d}), \mathrm{Rap}$ $(0.25 \mathrm{mg} / \mathrm{kg} / \mathrm{d})$, or Met $(250 \mathrm{mg} / \mathrm{kg} / \mathrm{d})$ combined with Rap $(0.25 \mathrm{mg} / \mathrm{kg} / \mathrm{d})$. (A) Tumor dimensions and animal weights were obtained at the indicated time points. (B) After 28-day treatment, the lysates extracted from these experimental xenograft tumors were collected and analyzed by Western blotting. (C) Huh7 cells were infected with lentiviruses to drive stable expression of either IPTG-inducible LacZ shRNA (shC) or IPTG-inducible CEBPD shRNA (shCD). Infected Huh7 cells were subcutaneously inoculated on the dorsal of 6-week-old NOD-SCID mice $(n=5)$ followed by intraperitoneal injection of $200 \mu 1$ IPTG $(0.53 \mathrm{mmol})$ every other day. Mice were then treated with or without Met $(250 \mathrm{mg} / \mathrm{kg} / \mathrm{d})$ combined with Rap $(0.25 \mathrm{mg} / \mathrm{kg} / \mathrm{d})$ via intraperitoneal injection. After 28-day treatment, mice were sacrificed and the tumor volume was measured. 
pathways, respectively, and reduce the development of drug resistance in HCC (Figure 7).

Importantly, studies showed that metformin can attenuate the occurrence of HCC and reduce human tumor xenograft growth [50-53]. However, the potent mechanism in response to metformin in liver cancer cells remains an open question. In this study, we found that metformin can induce autophagy through CEBPD upregulation, and the combinatorial treatment of metformin and rapamycin can enhance autophagic cell death of HCC. In addition, CEBPD is thought to be a potent tumor suppressor, and its expression is downregulated in several cancers, including breast cancer [54], leukemia [55], cervical cancer [56], and hepatocellular carcinoma [57]. Several studies indicated that autophagy contributes to pro-apoptosis in breast cancer [58] and cervical cancer [59] and limits proliferation in leukemia [60]. Therefore, an issue whether the CEBPD-induced autophagy contributes to the death of breast cancer, leukemia and cervical cancer needs to be further dissected.

\section{MATERIALS AND METHODS}

\section{Materials}

TRIzol RNA extraction reagent, SuperScript ${ }^{\mathrm{TM}}$ III, Dulbecco's modified Eagle's medium, Opti-MEM medium, and caspase-3/7 green detection reagent were obtained from Invitrogen (Carlsbad, CA, USA). Fetal bovine serum was purchased from HyClone Laboratories (Logan, UT, USA). Metformin, rapamycin and chloroquine were purchased from Sigma (St. Louis, MO, USA). Compound C (AMPK inhibitor) was purchased from Calbiochem (San Diego, CA, USA). SKI-606 was purchased from Selleck Chemicals (Houston, TX, USA). Antibodies against CEBPD, cyclin D1, AMPK, p-AMPK and $\beta$-actin were purchased from Santa Cruz Biotechnology (Santa Cruz, CA, USA). Antibodies against LC3B, p27, and p84 were purchased from GeneTex (Irvine, CA, USA). Antibodies against ATG3 and p62 were purchased from Cell Signaling Technology (Beverly, MA, USA). Antibodies against HA, Src and p-Src were purchased from Covance (Berkeley, CA, USA). Antibodies against $\alpha$-tubulin and mouse IgG were purchased from Sigma.

\section{Cell culture}

The human hepatocellular carcinoma cell lines Huh7, HepG2 and Hep3B were maintained in Dulbecco's modified Eagle's medium (DMEM) supplemented with $10 \%$ fetal bovine serum (FBS), $100 \mu \mathrm{g} / \mathrm{ml}$ streptomycin, and 100 units $/ \mathrm{ml}$ penicillin at $37^{\circ} \mathrm{C}$ and $5 \% \mathrm{CO}_{2}$.

\section{Lentiviral shRNA knockdown}

The virus was produced from Phoenix Ampho cells using Mirus Bio TransIT-2020 and cotransfected with various short hairpin RNA (shRNA) expression vectors in combination with pMD2.G and psPAX2 vectors and the pLKO.1-shRNA expression vectors. The short interfering RNA sequences targeting LacZ, CEBPD and LC3B were subcloned into the lentiviral

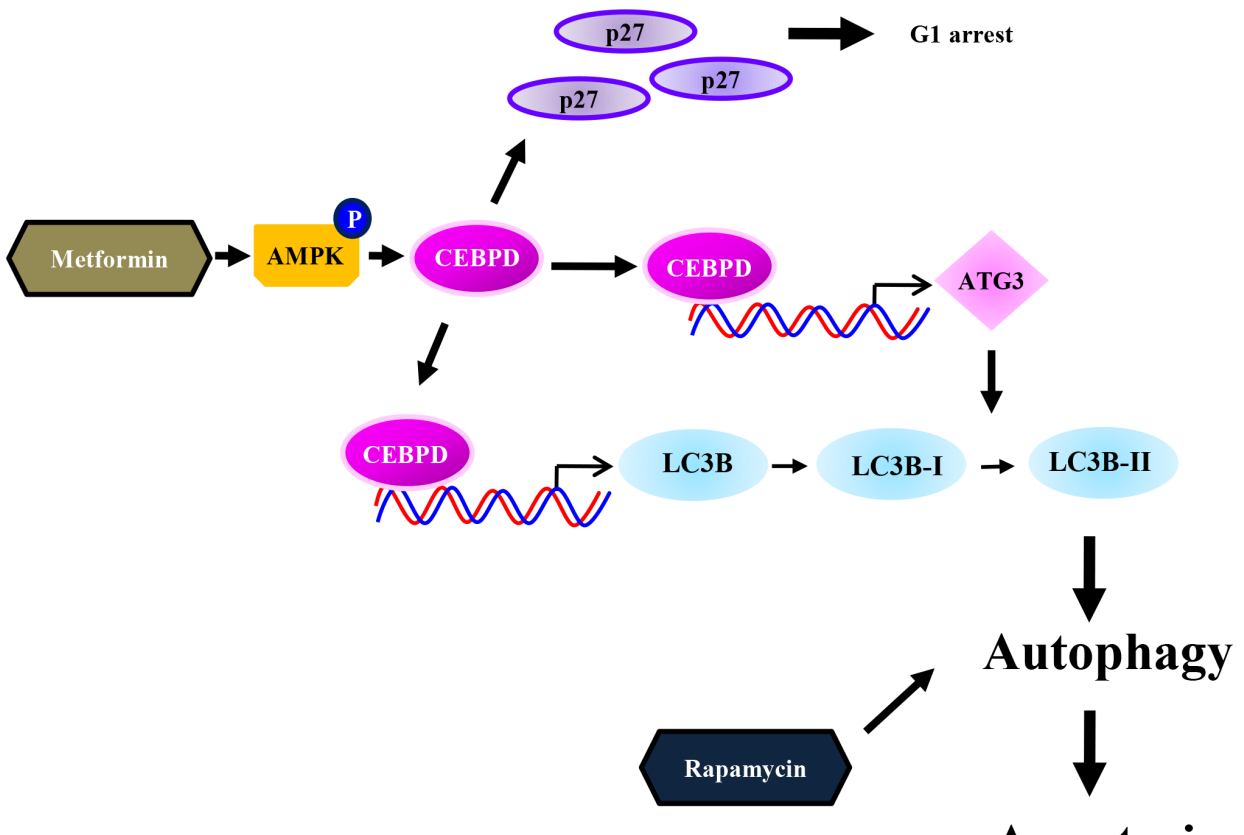

Apoptosis

Figure 7: Schematic model of the molecular mechanism by which the combination of metformin and rapamycin enhances anticancer effects. 
expression vector $\mathrm{pLKO}$.1. The short interfering RNA sequences are as follows: shLacZ (shZ): 5'-CCGGTG TTCGCATTATCCGAACCATCTCGAGATGGTTCGGA TAATGCGAACATTTTTG-3'; shCEBPD (shD): 5-CCG GGCCGACCTCTTCAACAGCAATCTCGAGATTGCT GTTGAAGAGGTCGGCTTTTT-3; shLC3B(shL): 5-CCG GCGCTTACAGCTCAATGCTAATCTCGAGATTAGCA TTGAGCTGTAAGCGTTTTTTG-3. The expression vectors and shRNAs were obtained from the National RNAi Core Facility located at the Genomic Research Center of Institute of Molecular Biology, Academia Sinica, Taiwan.

\section{Plasmid transfection and reporter assays}

Several varieties of human CEBPD reporters were constructed in our lab [61]. The reporters bearing different fragments of the human ATG3 and LC3B promoters were generated by PCR with genomic DNA as the template. The primers for the PCR reaction are as follows: ATG3 promoter (WT) 5'-CTCACTGCAACCCCTACCTA-3' and 5'-GAAGCGGACGCACACGC-3'; ATG3 promoter (D1) 5'-CCTTCTAGTCACACATGCGC-3' and 5'- GAA GCGGACGCACACGC-3'; ATG3 promoter (D2) 5'-GAA GCAAAGCGAGGACAGAC' and 5'- GAAGCGGACGC ACACGC-3'; LC3B promoter (WT) 5'-CGGGAGGC TGAGGCAGGAGGATCC-3' and 5'-CGATAGCCACTT CCCTTGTATCTC-3'; LC3B promoter (D1) 5'-AGTCGC CACAGACGACCTAA-3' and 5'-CGATAGCCACTTCC CTTGTATCTC-3'. After verification by sequencing, the PCR products were cloned into the multiple cloning sites of pGL3-basic vector. These reporters were transfected into Huh7 cells by Turbofect according to the manufacturer's suggestions. Transfectants were cultured in complete medium with or without treatment for $6 \mathrm{~h}$. Luciferase activity was measured in the lysates of transfectants.

\section{Reverse transcription (RT)-PCR}

We isolated total RNA from stimulated Huh7 cells and used CEBPD-, ATG3-, and LC3B-specific primers for analysis. Glyceraldehyde-3-phosphate dehydrogenase (GAPDH) primers were used as a control. The specific primers used were as follows: human CEBPD: 5'-AGCGCAACAACATCGCCGTG-3' and 5'-GTCGGGTCTGAGGTATGGGTC-3'; ATG3: 5'-CA ACGGCAGCCTTTAACAGT-3' and 5'-CAAGTTCTCCC CCTCCTTCT-3'; LC3B: 5'-AGCAGCATCCAACCAAA ATC-3' and 5'-CTGTGTCCGTTCACCAACAG-3'; human GAPDH: 5'- CCATCACCATCTTCCAGGAG-3' and 5'- CCTGCTTCACCACCTTCTTG-3'. Amounts of PCR product were determined using the IS- 1000 digital imaging system (Alpha Innotech, San Leandro, CA, USA).
Quantitative real time polymerase chain reaction (Q-PCR)

Real-time PCR was performed using KAPA SYBR FAST qPCR Master Mix and the CFX95 ${ }^{\text {TM }}$ Real-Time PCR Detection machine. Primer sequences were as follows: CEBPD: 5'-GCCATGTACGACGACGAGAG-3' and 5'-TGTGATTGCTGTTGAAGAGGTC-3'; GAPDH: 5'-C CACCCAGAAGACTGTGGAT-3' and 5'-TTCAGCTCA GGGATGACCTT-3'. Q-PCR was conducted with the following amplification conditions: 1 cycle of $95^{\circ} \mathrm{C}$ for $10 \mathrm{~min}, 39$ cycles of $95^{\circ} \mathrm{C}$ for $5 \mathrm{sec}, 60^{\circ} \mathrm{C}$ for $10 \mathrm{sec}$ and $72^{\circ} \mathrm{C}$ for $15 \mathrm{sec}$. Finally, a melting curve was performed to check for the presence of a single product from each reaction. Expression levels of the genes of interest were then compared to expression of GAPDH.

\section{Chromatin immunoprecipitation (ChIP)}

ChIP assay was conducted as described by Ju-Ming Wang and colleagues [62]. Briefly, the sheared chromatin fragments were immunoprecipitated with antibodies specific to CEBPD or control mouse IgG at $4^{\circ} \mathrm{C}$ overnight. After dissociating the DNA from immunoprecipitated chromatin, the DNA was amplified by PCR with two pairs of specific primers: ATG3 (F) 5'-CTCACTGCAACCCCTACCTA-3' and ATG3 (R) 5'-AAAGTGCTGGGATTACAGG-3'; the negative control for ATG3 (F) 5'-GGGACATGCGGGCAACAATA-3' and the negative control for ATG3 (R) 5'-CACTCTCCGAG AAACACCCA-3'; LC3B (F) 5'-GAGACACATTGGCC ACAGGC-3' and LC3B (R) 5'-AGTCGCCACAGACGA CCTAA-3'; the negative control for LC3B (F) 5'-CCAC CTGCACAAATGCACCG-3' and the negative control for LC3B (R) 5'-TGTATTCCCAGCTACTGGGG-3'. The PCR conditions were as follows: 1 cycle of $3 \mathrm{~min}$ at $94^{\circ} \mathrm{C}$; 36 cycles of $94^{\circ} \mathrm{C}$ for $30 \mathrm{sec}, 56^{\circ} \mathrm{C}$ for $30 \mathrm{sec}, 72^{\circ} \mathrm{C}$ for $40 \mathrm{sec}$, and 1 cycle of $10 \mathrm{~min}$ at $72^{\circ} \mathrm{C}$.

\section{Western blot analysis}

Cell lysates were prepared from control and chemically treated cells. Briefly, cells were lysed in modified RIPA buffer [50 mM Tris- $\mathrm{HCl}$ (pH 7.4), $150 \mathrm{mM}$ $\mathrm{NaCl}, 1 \mathrm{mM}$ EDTA, $1 \%$ Nonidet P-40, $0.25 \%$ sodium deoxycholate, $1 \mathrm{mM}$ DTT, $1 \mathrm{mM}$ phenylmethylsulfonyl fluoride, $1 \mu \mathrm{g} / \mathrm{ml}$ aprotinin and $1 \mu \mathrm{g} / \mathrm{ml}$ of leupeptin] to be analyzed. Following lysis, the lysates were resolved on an SDS-containing 10\% polyacrylamide gel, transferred to polyvinylidene difluoride nylon membrane, and probed with specific antibodies at $4^{\circ} \mathrm{C}$ overnight. The specific bands were detected by horseradish peroxidaseconjugated antibody and revealed by an enhanced chemiluminescence (ECL) Western blot system from Pierce (Rockford, IL). 


\section{mRNA half-life assay}

Huh7 cells were treated with or without metformin for $2 \mathrm{~h}$. Then, $1 \mu \mathrm{g} / \mathrm{ml}$ actinomycin D was added to block newly synthesized RNA. Total RNA was isolated at the indicated times and examined by qPCR.

\section{Protein stability}

Huh7 cells were treated with or without metformin for $2 \mathrm{~h}$. Then, $10 \mu \mathrm{g} / \mathrm{ml}$ cycloheximide was added to block newly synthesized protein. Cell lysates were isolated at indicated times and analyzed by Western blotting assay.

\section{Cell viability}

Huh7 cells were seeded $5 \times 10^{3}$ cells/ well in 96well plates. Cells were treated with various concentrations $(0,5,10$ and $20 \mathrm{mM})$ of metformin for $48 \mathrm{~h}$ or with the combination of $5 \mathrm{mM}$ metformin and $10 \mu \mathrm{M}$ rapamycin for $48 \mathrm{~h}$. The experimental cells were incubated with diluted MTT reagent (3-(4,5-dimethylthiazol-2-yl)-2,5diphenyltetrazolium bromide) at $37^{\circ} \mathrm{C}$ for $3.5 \mathrm{~h}$. The samples were then measured spectrophotometrically at $595 \mathrm{~nm}$ by an ELISA plate reader.

\section{Flow cytometry analysis}

Typical cell cycle histograms were analyzed with flow cytometry after treatment with metformin alone or combined with rapamycin for the indicated times. Apoptotic cell death of Huh7 cells was determined by analyzing the sub-G1 populations. After chemical treatment, cells were resuspended in PBS and fixed in ice-cold $75 \%$ ethanol at $-20^{\circ} \mathrm{C}$. Later, cell pellets were collected by centrifugation and resuspended in propidium iodide solution $(0.1 \%$ Triton X-100 in PBS, $0.2 \mathrm{mg} / \mathrm{ml}$ RNase $\mathrm{A}$ and $20 \mu \mathrm{g} / \mathrm{ml}$ propidium iodide) at room temperature for $1 \mathrm{~h}$. Fluorescence emitted from propidium iodide-DNA complexes was quantified after excitation of the fluorescent dye by FACScan cytometry (CellLab Quanta $^{\mathrm{TM}} \mathrm{SC}$, Beckman Coulter).

\section{Caspase-3/7 activity assay}

After treatment with or without metformin for $48 \mathrm{~h}$, cells were labeled with $2 \mu \mathrm{M}$ CellEvent ${ }^{\mathrm{TM}}$ caspase-3/7 green detection reagent in complete medium for $1 \mathrm{~h}$ at $37^{\circ} \mathrm{C}$ in the dark. The fluorogenic response was detected on a Fluoroskan Ascent ${ }^{\mathrm{TM}}$ FL Microplate Fluorometer and Luminometer (ThermoLabsystem) with an absorption/ emission of $485 / 538 \mathrm{~nm}$.

\section{Fluorescence microscopy}

The pEGFP-LC3 plasmid was a gift obtained from Dr. Tamotsu Yahsimori and Noboru Mizushima [63]. A fused LC3B promoter-driven GFP-LC3B expression vector was generated by replacing the CMV promoter region with LC3B promoter fragment from -978 to +139 bp obtained by $\mathrm{PCR}$ and the primers were described as follows: LC3B/AseI-978: 5'-GTTATTAATAGTCGGGAGGCTG AGGCAGGAGGAT-3', LC3B/AgeI+139: 5'-GCTACC GGTCGCCGATAGCCACTTCCCTTGTATC-3'. Huh7 cells transfected with GFP-LC3B or its derived plasmids were grown on glass coverslips, co-transfected with HA/ HA-CEBPD or treated with metformin $(5 \mathrm{mM})$ for $6 \mathrm{~h}$, and then examined under a fluorescence microscope. Images shown are representative of three independent experiments. The fold changes of the average numbers of puncta per positive cells were calculated with 50 individual cells.

\section{Animal studies}

Male, six-week-old NOD/SCID mice were obtained from the Laboratory Animal Center of National Cheng Kung University, Tainan, Taiwan. Huh7 cells $\left(2 \times 10^{6}\right)$ in $0.2 \mathrm{ml}$ PBS were inoculated subcutaneously into the right flank of the mice. After 10 days, when macroscopic tumors (50-100 $\left.\mathrm{mm}^{3}\right)$ had formed, animals ( $n=5$ per group) were placed randomly into four groups as follows: (1) the control group, which received identical volumes of vehicle (DMSO); (2) the metformin treatment group, which was treated with $250 \mathrm{mg} / \mathrm{kg} /$ day metformin; (3) the rapamycin treatment group, which was treated with rapamycin at doses of $0.25 \mathrm{mg} / \mathrm{kg} / \mathrm{day}$; and (4) the combined treatment group, which was injected with metformin combined with rapamycin. Treatment was given to all groups intraperitoneally every day for four weeks. Animal weight and tumor dimensions were measured every four days with calipers, and tumor volumes were estimated using two-dimensional measurements of length and width and were calculated with the formula: $\left[l \times(w)^{2}\right] \times 0.52$, where $l$ is length and $w$ is width.

\section{Statistical analysis}

All experiments were repeated at least three times, and data were analyzed for statistical significance by twotailed unpaired Student's $t$ test using Prism 5 software. The data were expressed as the means \pm SEM. Differences were considered statistically significant when indicated by asterisks. Statistical significance was accepted for $P<0.05$ $(*), P<0.01(* *)$, or $P<0.001(* * *)$.

\section{ACKNOWLEDGMENTS AND FUNDING}

This work was supported by grants from the Ministry of Science and Technology (MOST 105-2321B-006-029 and MOST 103-2320-B-006-034-MY3), Liver Disease Prevention \& Treatment Research Foundation, Taiwan and partly by grant NHRI-EX105-10422BI from the National Health Research Institutes. 


\section{CONFLICTS OF INTEREST}

The authors declare no conflicts of interest.

\section{REFERENCES}

1. Lozy F, Karantza V. Autophagy and cancer cell metabolism. Seminars in cell \& developmental biology. 2012; 23:395-401.

2. Cui J, Gong Z, Shen HM. The role of autophagy in liver cancer: molecular mechanisms and potential therapeutic targets. Biochimica et biophysica acta. 2013; 1836:15-26.

3. Bjorkoy G, Lamark T, Brech A, Outzen H, Perander M, Overvatn A, Stenmark H, Johansen T. p62/SQSTM1 forms protein aggregates degraded by autophagy and has a protective effect on huntingtin-induced cell death. The Journal of cell biology. 2005; 171:603-614.

4. Lee YJ, Hah YJ, Kang YN, Kang KJ, Hwang JS, Chung WJ, Cho KB, Park KS, Kim ES, Seo HY, Kim MK, Park KG, Jang BK. The autophagy-related marker LC3 can predict prognosis in human hepatocellular carcinoma. PloS one. 2013; 8:e81540.

5. Pernicova I, Korbonits M. Metformin — mode of action and clinical implications for diabetes and cancer. Nature reviews Endocrinology. 2014; 10:143-156.

6. Donadon V, Balbi M, Mas MD, Casarin P, Zanette G. Metformin and reduced risk of hepatocellular carcinoma in diabetic patients with chronic liver disease. Liver international. 2010; 30:750-758.

7. Evans JM, Donnelly LA, Emslie-Smith AM, Alessi DR, Morris AD. Metformin and reduced risk of cancer in diabetic patients. BMJ (Clinical research ed). 2005; 330:1304-1305.

8. Libby G, Donnelly LA, Donnan PT, Alessi DR, Morris AD, Evans JM. New users of metformin are at low risk of incident cancer: a cohort study among people with type 2 diabetes. Diabetes care. 2009; 32:1620-1625.

9. Chen HP, Shieh JJ, Chang CC, Chen TT, Lin JT, Wu MS, Lin $\mathrm{JH}, \mathrm{Wu} \mathrm{CY}$. Metformin decreases hepatocellular carcinoma risk in a dose-dependent manner: populationbased and in vitro studies. Gut. 2013; 62:606-615.

10. Saito T, Chiba T, Yuki K, Zen Y, Oshima M, Koide S, Motoyama T, Ogasawara S, Suzuki E, Ooka Y, Tawada A, Tada M, Kanai F, et al. Metformin, a diabetes drug, eliminates tumor-initiating hepatocellular carcinoma cells. PloS one. 2013; 8:e70010.

11. Shi WY, Xiao D, Wang L, Dong LH, Yan ZX, Shen ZX, Chen SJ, Chen Y, Zhao WL. Therapeutic metformin/AMPK activation blocked lymphoma cell growth via inhibition of mTOR pathway and induction of autophagy. Cell death \& disease. 2012; 3:e275.

12. Tomic T, Botton T, Cerezo M, Robert G, Luciano F, Puissant A, Gounon P, Allegra M, Bertolotto C, Bereder JM, Tartare-Deckert S, Bahadoran P, Auberger P, et al. Metformin inhibits melanoma development through autophagy and apoptosis mechanisms. Cell death \& disease. 2011; 2:e199.
13. Sivko GS, DeWille JW. CCAAT/Enhancer binding protein delta (c/EBPdelta) regulation and expression in human mammary epithelial cells: I. "Loss of function" alterations in the c/EBPdelta growth inhibitory pathway in breast cancer cell lines. Journal of cellular biochemistry. 2004; 93:830-843.

14. Agrawal S, Hofmann WK, Tidow N, Ehrich M, van den Boom D, Koschmieder S, Berdel WE, Serve H, MullerTidow C. The C/EBPdelta tumor suppressor is silenced by hypermethylation in acute myeloid leukemia. Blood. 2007; 109:3895-3905.

15. Pan YC, Li CF, Ko CY, Pan MH, Chen PJ, Tseng JT, Wu WC, Chang WC, Huang AM, Sterneck E, Wang JM. CEBPD reverses $\mathrm{RB} / \mathrm{E} 2 \mathrm{~F} 1$-mediated gene repression and participates in HMDB-induced apoptosis of cancer cells. Clinical cancer research. 2010; 16:5770-5780.

16. Ko CY, Hsu HC, Shen MR, Chang WC, Wang JM. Epigenetic silencing of CCAAT/enhancer-binding protein delta activity by YY1/polycomb group/DNA methyltransferase complex. The Journal of biological chemistry. 2008; 283:30919-30932.

17. Chuang CH, Wang WJ, Li CF, Ko CY, Chou YH, Chuu CP, Cheng TL, Wang JM. The combination of the prodrugs perforin-CEBPD and perforin-granzyme B efficiently enhances the activation of caspase signaling and kills prostate cancer. Cell death \& disease. 2014; 5:e1220.

18. Yang X, Sun D, Tian Y, Ling S, Wang L. Metformin sensitizes hepatocellular carcinoma to arsenic trioxideinduced apoptosis by downregulating $\mathrm{Bcl} 2$ expression. Tumour biology. 2015; 36:2957-2964.

19. Shintani T, Klionsky DJ. Autophagy in health and disease: a double-edged sword. Science (New York, NY). 2004; 306:990-995.

20. Gery S, Tanosaki S, Hofmann WK, Koppel A, Koeffler HP. C/EBPdelta expression in a BCR-ABL-positive cell line induces growth arrest and myeloid differentiation. Oncogene. 2005; 24:1589-1597.

21. Ikezoe T, Gery S, Yin D, O'Kelly J, Binderup L, Lemp N, Taguchi H, Koeffler HP. CCAAT/enhancer-binding protein delta: a molecular target of 1,25-dihydroxyvitamin D3 in androgen-responsive prostate cancer LNCaP cells. Cancer research. 2005; 65:4762-4768.

22. Hsiao YW, Li CF, Chi JY, Tseng JT, Chang Y, Hsu LJ, Lee $\mathrm{CH}$, Chang TH, Wang SM, Wang DD, Cheng HC, Wang JM. CCAAT/enhancer binding protein delta in macrophages contributes to immunosuppression and inhibits phagocytosis in nasopharyngeal carcinoma. Science signaling. 2013; 6:ra59.

23. Sarkar TR, Sharan S, Wang J, Pawar SA, Cantwell CA, Johnson PF, Morrison DK, Wang JM, Sterneck E. Identification of a Src tyrosine kinase/SIAH2 E3 ubiquitin ligase pathway that regulates $\mathrm{C} / \mathrm{EBPdelta}$ expression and contributes to transformation of breast tumor cells. Molecular and cellular biology. 2012; 32:320-332.

24. Amaravadi RK. Autophagy-induced tumor dormancy in ovarian cancer. The Journal of clinical investigation. 2008; 118:3837-3840. 
25. Tsujimoto Y, Shimizu S. Another way to die: autophagic programmed cell death. Cell death and differentiation. 2005; 12:1528-1534.

26. Law BK. Rapamycin: an anti-cancer immunosuppressant? Critical reviews in oncology/hematology. 2005; 56:47-60.

27. Wu L, Feng Z, Cui S, Hou K, Tang L, Zhou J, Cai G, Xie Y, Hong Q, Fu B, Chen X. Rapamycin upregulates autophagy by inhibiting the mTOR-ULK1 pathway, resulting in reduced podocyte injury. PloS one. 2013; 8:e63799.

28. Lonardo A, Ballestri S, Targher G, Loria P. Diagnosis and management of cardiovascular risk in nonalcoholic fatty liver disease. Expert review of gastroenterology \& hepatology. 2014:1-22.

29. Settembre C, De Cegli R, Mansueto G, Saha PK, Vetrini F, Visvikis O, Huynh T, Carissimo A, Palmer D, Klisch TJ, Wollenberg AC, Di Bernardo D, Chan L, et al. TFEB controls cellular lipid metabolism through a starvationinduced autoregulatory loop. Nature cell biology. 2013; 15:647-658.

30. Polager S, Ofir M, Ginsberg D. E2F1 regulates autophagy and the transcription of autophagy genes. Oncogene. 2008; 27:4860-4864.

31. Xu P, Das M, Reilly J, Davis RJ. JNK regulates FoxOdependent autophagy in neurons. Genes \& development. 2011; 25:310-322.

32. Milani M, Rzymski T, Mellor HR, Pike L, Bottini A, Generali D, Harris AL. The role of ATF4 stabilization and autophagy in resistance of breast cancer cells treated with Bortezomib. Cancer research. 2009; 69:4415-4423.

33. Ma D, Panda S, Lin JD. Temporal orchestration of circadian autophagy rhythm by C/EBPbeta. The EMBO journal. 2011; 30:4642-4651.

34. Rouschop KM, van den Beucken T, Dubois L, Niessen H, Bussink J, Savelkouls K, Keulers T, Mujcic H, Landuyt W, Voncken JW, Lambin P, van der Kogel AJ, Koritzinsky M, et al. The unfolded protein response protects human tumor cells during hypoxia through regulation of the autophagy genes MAP1LC3B and ATG5. The Journal of clinical investigation. 2010; 120:127-141.

35. Yeatman TJ. A renaissance for SRC. Nature reviews Cancer. 2004; 4:470-480.

36. Zhang S, Yu D. Targeting Src family kinases in anticancer therapies: turning promise into triumph. Trends in pharmacological sciences. 2012; 33:122-128.

37. Fung C, Chen X, Grandis JR, Duvvuri U. EGFR tyrosine kinase inhibition induces autophagy in cancer cells. Cancer biology \& therapy. 2012; 13:1417-1424.

38. Wu Z, Chang PC, Yang JC, Chu CY, Wang LY, Chen NT, Ma AH, Desai SJ, Lo SH, Evans CP, Lam KS, Kung HJ. Autophagy Blockade Sensitizes Prostate Cancer Cells towards Src Family Kinase Inhibitors. Genes \& cancer. 2010; 1:40-49.

39. Kim J, Lee J, Kim C, Choi J, Kim A. Anti-cancer effect of metformin by suppressing signaling pathway of HER 2 and HER3 in tamoxifen-resistant breast cancer cells. Tumour biology. 2016; 37:5811-5819.
40. Balamurugan K, Sterneck E. The many faces of C/EBPdelta and their relevance for inflammation and cancer. International journal of biological sciences. 2013; 9:917-933.

41. Holohan C, Van Schaeybroeck S, Longley DB, Johnston PG. Cancer drug resistance: an evolving paradigm. Nature reviews Cancer. 2013; 13:714-726.

42. Qu H, Yang X. Metformin Inhibits Angiogenesis Induced by Interaction of Hepatocellular Carcinoma with Hepatic Stellate Cells. Cell biochemistry and biophysics. 2015; 71:931-936.

43. Hsieh SC, Tsai JP, Yang SF, Tang MJ, Hsieh YH. Metformin inhibits the invasion of human hepatocellular carcinoma cells and enhances the chemosensitivity to sorafenib through a downregulation of the ERK/JNK-mediated NFkappaB-dependent pathway that reduces uPA and MMP-9 expression. Amino acids. 2014; 46:2809-2822.

44. Zhang ZY, Hong D, Nam SH, Kim JM, Paik YH, Joh JW, Kwon CH, Park JB, Choi GS, Jang KY, Park CK, Kim SJ. SIRT1 regulates oncogenesis via a mutant p53-dependent pathway in hepatocellular carcinoma. Journal of hepatology. 2015; 62:121-130.

45. Feng Y, Ke C, Tang Q, Dong H, Zheng X, Lin W, Ke J, Huang J, Yeung SC, Zhang H. Metformin promotes autophagy and apoptosis in esophageal squamous cell carcinoma by downregulating Stat 3 signaling. Cell death \& disease. 2014; 5:e1088.

46. Dowling RJ, Zakikhani M, Fantus IG, Pollak M, Sonenberg N. Metformin inhibits mammalian target of rapamycin-dependent translation initiation in breast cancer cells. Cancer research. 2007; 67:10804-10812.

47. Gotlieb WH, Saumet J, Beauchamp MC, Gu J, Lau S, Pollak MN, Bruchim I. In vitro metformin anti-neoplastic activity in epithelial ovarian cancer. Gynecologic oncology. 2008; 110:246-250.

48. Luo Z, Zang M, Guo W. AMPK as a metabolic tumor suppressor: control of metabolism and cell growth. Future oncology (London, England). 2010; 6:457-470.

49. Carter HN, Hood DA. Contractile activity-induced mitochondrial biogenesis and mTORC1. American journal of physiology Cell physiology. 2012; 303:C540-547.

50. Donadon V, Balbi M, Ghersetti M, Grazioli S, Perciaccante A, Della Valentina G, Gardenal R, Dal Mas M, Casarin P, Zanette G, Miranda C. Antidiabetic therapy and increased risk of hepatocellular carcinoma in chronic liver disease. World journal of gastroenterology. 2009; 15:2506-2511.

51. Lai SW, Chen PC, Liao KF, Muo CH, Lin CC, Sung FC. Risk of hepatocellular carcinoma in diabetic patients and risk reduction associated with anti-diabetic therapy: a population-based cohort study. The American journal of gastroenterology. 2012; 107:46-52.

52. Fujita K, Iwama H, Miyoshi H, Tani J, Oura K, Tadokoro T, Sakamoto T, Nomura T, Morishita A, Yoneyama H, Masaki T. Diabetes mellitus and metformin in hepatocellular 
carcinoma. World journal of gastroenterology. 2016; 22:6100-6113.

53. Qu Z, Zhang Y, Liao M, Chen Y, Zhao J, Pan Y. In vitro and in vivo antitumoral action of metformin on hepatocellular carcinoma. Hepatology research. 2012; 42:922-933.

54. Miyoshi H, Kato K, Iwama H, Maeda E, Sakamoto T, Fujita K, Toyota Y, Tani J, Nomura T, Mimura S, Kobayashi M, Morishita A, Kobara H, et al. Effect of the anti-diabetic drug metformin in hepatocellular carcinoma in vitro and in vivo. International journal of oncology. 2014; 45:322-332.

55. Cheng J, Huang T, Li Y, Guo Y, Zhu Y, Wang Q, Tan X, Chen W, Zhang Y, Cheng W, Yamamoto T, Jing X, Huang J. AMP-activated protein kinase suppresses the in vitro and in vivo proliferation of hepatocellular carcinoma. PloS one. 2014; 9:e93256.

56. Miyoshi H, Kato K, Iwama H, Maeda E, Sakamoto T, Fujita K, Toyota Y, Tani J, Nomura T, Mimura S, Kobayashi M, Morishita A, Kobara H, Mori H, Yoneyama H, Deguchi A, et al. Effect of the anti-diabetic drug metformin in hepatocellular carcinoma in vitro and in vivo. International journal of oncology. 2014; 45:322-32.

57. Kim EH, Kim MS, Cho CK, Jung WG, Jeong YK, Jeong JH. Low and high linear energy transfer radiation sensitization of HCC cells by metformin. Journal of radiation research. 2014; 55:432-442.

58. Harris K, Smith L. Safety and efficacy of metformin in patients with type 2 diabetes mellitus and chronic hepatitis $\mathrm{C}$. The Annals of pharmacotherapy. 2013; 47:1348-1352.
59. Cai X, Hu X, Cai B, Wang Q, Li Y, Tan X, Hu H, Chen X, Huang J, Cheng J, Jing X. Metformin suppresses hepatocellular carcinoma cell growth through induction of cell cycle G1/G0 phase arrest and p21CIP and p27KIP expression and downregulation of cyclin D1 in vitro and in vivo. Oncology reports. 2013; 30:2449-2457.

60. Kim JH, Alam MM, Park DB, Cho M, Lee SH, Jeon YJ, Yu DY, Kim TD, Kim HY, Cho CG, Lee DH. The Effect of Metformin Treatment on CRBP-I Level and Cancer Development in the Liver of HBx Transgenic Mice. The Korean journal of physiology \& pharmacology. 2013; 17:455-461.

61. Wang JM, Tseng JT, Chang WC. Induction of human NFIL6beta by epidermal growth factor is mediated through the p38 signaling pathway and cAMP response element-binding protein activation in A431 cells. Molecular biology of the cell. 2005; 16:3365-3376.

62. Wang JM, Ko CY, Chen LC, Wang WL, Chang WC. Functional role of NF-IL6beta and its sumoylation and acetylation modifications in promoter activation of cyclooxygenase 2 gene. Nucleic acids research. 2006; 34:217-231.

63. Kabeya Y, Mizushima N, Ueno T, Yamamoto A, Kirisako T, Noda T, Kominami E, Ohsumi Y, Yoshimori T. LC3, a mammalian homologue of yeast Apg8p, is localized in autophagosome membranes after processing. The EMBO journal. 2000; 19:5720-5728. 